\title{
Evaluation on Transformation Efficiency of Resource-based Cities in Shanxi Province
}

\author{
Zhaoyuan Zhang \\ Shanxi University of Finance and Economics, Taiyuan,Shanxi,China
}

Keywords: Resource-based city; transformation efficiency; dea

\begin{abstract}
In order to explore the efficient and reasonable transformation path of resource-based cities in Shanxi Province, this paper uses the super-efficient SBM model to evaluate the transformation effects of 10 resource-based cities in Shanxi Province from 2012 to 2016. The results show that the overall transformation achieved initial results, but the effect is not significant; the optimization analysis of its production frontiers found that Datong, Jinzhong and Changzhi have optimization potential.
\end{abstract}

\section{山西省资源型城市转型效率评价}

\author{
张照远 \\ 山西财经大学工商管理学院，太原，山西，中国
}

关键词：资源型城市; 转型效率; dea

中文摘要.为探索山西省资源型城市高效合理的转型路径, 本文采用超效率SBM模型, 对 2012-2016年山西省10个资源型城市的转型效果进行评价。结果表明，总体上转型取得初步成 效, 但是效果并不显著; 对其生产前沿面投入优化分析发现, 大同, 晋中, 长治具有优化潜 力。

\section{1. 引言}

资源型城市是指依赖于矿产、森林等自然资源，以对其进行开采、加工为主导产业的城 市。资源对资源型城市的兴起与发展起巨大的推动作用，为国家工业体系的构建以及社会经 济的发展也作出了重要贡献。然而资源型城市对资源的过度依赖阻碍了城市的进一步发展, 对资源的过度开采导致生态环境遭到破坏, 并且有的城市资源利用效率低, 转型发展的动力 不强。针对这一现象, 2013年国务院印发了《全国资源型城市可持续发展规划(2013-2020年)》, 贯彻五大发展理念, 对资源型城市的转型发展提出了新的要求。资源型城市的转型效率关系 到社会、经济以及环境等各个方面, 因此对资源型城市转型效率的测度可以直观地反应出城 市的转型效果，为资源型城市的下一步发展提供依据。

资源型城市的转型效率是近年来学者们研究的热点问题。高见曾贤刚运用熵值法和聚类 分析法对 16 个煤炭资源枯竭型城市进行了绿色转型绩效评价和区域差异研究, 并提出相关的 绿色转型建议 ${ }^{11]}$ 。孙青林以淮南市为例, 分析淮南市的特征和发展面临的问题, 从总体规划 的视角对淮南市的转型发展提出五条规划对策 ${ }^{[2]}$ 。 郝祖涛通过专家群决策和AHP方法，从民 生满意度视角对湖北黄石市的转型绩效进行测度 ${ }^{[3]}$ 。徐君构建供给侧结构性改革驱动资源型 城市转型的综合机制, 为资源型城市转型提供了理论参考 ${ }^{[4]}$ 。曹建忠基于坏产出动态SBM模 
型, 评价不同类型的资源型城市转型效率, 结果表明城市基础条件会影响城市的转型效率, 不同类型资源型城市应采取不同手段提高转型效率 ${ }^{[5]}$ 。

不同学者从不同的视角对资源型城市的转型效率进行评价, 且采用的模型各不相同。本 文以山西省资源型城市 (地级市) 为例, 为了避免传统的CCR、SBM的不足, 运用超效率结 合SBM模型分析其转型效率。

\section{2. 研究模型}

转型效率可以用转型效果来衡量, 即在投入一定的情况下得到更多产出的效率。假设将s 个资源型城市作为测算对象, 其投入和产出分别设定为 $\mathrm{n}$ 和 $\mathrm{m} 。 \mathrm{x}_{i q}$ 和 $\mathrm{y}_{j q}$ 分别表示的是第 $q$ 个资 源型城市的第 $i$ 个投入要素和第 $j$ 个产出要素。 $\mathrm{n}$ 个输入的权重为 $\mathrm{v}_{\mathrm{i}}, \mathrm{m}$ 个输出的权重为 $\mathrm{u}_{\mathrm{j}}, \mathrm{X}_{\mathrm{k}}$ $=\left(\mathrm{x}_{1 \mathrm{k}}, \mathrm{x}_{2 \mathrm{k}}, \mathrm{x}_{3 \mathrm{k}}, \cdots, \mathrm{x}_{\mathrm{nk}}\right)^{\mathrm{T}}, \mathrm{Y}_{\mathrm{k}}=\left(\mathrm{y}_{1 \mathrm{k}}, \mathrm{y}_{2 \mathrm{k}}, \mathrm{y}_{3 k}, \cdots, \mathrm{y}_{\mathrm{mk}}\right)^{\mathrm{T}}, \mathrm{v}_{\mathrm{i}}=\left(\mathrm{v}_{1}, \mathrm{v}_{2}, \cdots, \mathrm{v}_{\mathrm{n}}\right)^{\mathrm{T}}, \mathrm{u}_{\mathrm{j}}=\left(\mathrm{u}_{1}, \mathrm{u}_{2}, \cdots, \mathrm{u}_{\mathrm{m}}\right)^{\mathrm{T}}$ 。

每个资源型城市的转型效果表示为:

$$
\max E_{k}=\frac{u^{T} y_{k}}{v^{T} x_{k}}=\frac{\sum_{r=1}^{n} u_{\mathrm{j}} \mathrm{y}_{\mathrm{jk}}}{\sum_{i=1}^{n} v_{\mathrm{i}} \mathrm{x}_{\mathrm{ik}}}, k=1,2, \cdots, s
$$

模型约束条件: $E_{k} \leq 1, \mathrm{v} \geq 0, \mathrm{u} \geq 01$ 。对权重系数进行调整从而确定在约束条件下 最大的效率值, 将上述模型转化为线性规划问题, 引入输入松弛变量 $s^{-}$和输出松弛变量 $S^{+}$, 则第 $\mathrm{k}$ 个资源型城市的效率值测算模型可以转化为线性规划问题:

\section{$\min \theta$}

$$
\text { s.t. }\left\{\begin{array}{c}
\sum_{\substack{i=1 \\
\mathrm{i} \neq \mathrm{k}}}^{s} X_{i}+\lambda_{i}+s^{+}=\theta X_{k} \\
\sum_{\substack{i=1 \\
\mathrm{i} \neq \mathrm{k}}}^{s} Y_{i}+\lambda_{i}-s^{-}=Y_{k} \\
\lambda_{i} \geq 0, \mathrm{i}=1,2, \cdots, s
\end{array}\right.
$$

公式中 $\theta$ 表示是第 $\mathrm{k}$ 个资源型城市的超效率值。超效率模型和传统 DEA 模型的最大区 别在于效率值可以大于 1 。

\section{3. 研究对象、指标选择与数据获取}

根据国务院发布的《全国资源型城市可持续发展规划（2013-2020年）》通知，选取山 西省属于资源型城市的地级市作为研究对象, 考虑到县级市的数据难以获取, 在保证分析结 果准确性的基础上剔除掉县级市的资源型城市。因此本文选取大同市、朔州市、阳泉市、长 治市、晋城市、忻州市、晋中市、临汾市、运城市和吕梁市从2012到2016年的相关数据作为 本文研究样本。

资源型城市转型效果的含义是资源型城市保证其经济平稳增长的基础上，考察资源型城 市对本地区资源依赖程度是否得到改善, 产业结构是否调整以及城市环境是否得到重视。因 此, 在构建指标体系时, 选择能够体现出第二、三产业融合度的投入产出指标, 即传统资源 产业是否有向第三产业、新兴产业过渡的趋势。

综合考虑，本文选取的投入指标为工业用电量、固定资产投资、第二产业从业人员。选 取的产出指标为地区生产总值、第三产业产值以及建成区绿化覆盖率。各投入产出指标数据 描述性统计分析 (见表1), 数据来源于《中国城市统计年鉴》、《山西统计年鉴》和各地市 统计年鉴。 
表1：投入产出指标描述性统计分析

\begin{tabular}{|l|r|r|r|r|r|r|}
\hline \multicolumn{1}{|c|}{ 指标 } & $\begin{array}{c}\text { 工业用电量 } \\
\text { (万千抯时) }\end{array}$ & $\begin{array}{c}\text { 固定资产投入 } \\
\text { (万元) }\end{array}$ & $\begin{array}{c}\text { 第二产业就业人 } \\
\text { 员 (人) }\end{array}$ & $\begin{array}{c}\text { 地区生产总值 } \\
\text { (万元) }\end{array}$ & $\begin{array}{c}\text { 第三产业产值 } \\
\text { (万元) }\end{array}$ & $\begin{array}{c}\text { 市绿化 } \\
\text { 率 } \\
(\%)\end{array}$ \\
\hline 个案 有效 & 50 & 50 & 50 & 50 & 50 & 50 \\
平均值 & 251787.02 & 9859607.24 & 296832.52 & 10079724.62 & 8917985.88 & 39.5192 \\
中位数 & 177875.00 & 10129192.50 & 315964.50 & 10338889.00 & 8684187.00 & 39.5750 \\
标准差 & 186327.735 & 2873123.971 & 75761.338 & 2150934.098 & 2766814.207 & 4.73251 \\
最小值 & 26179 & 3343212 & 149956 & 5957008 & 4062236 & 24.63 \\
最大值 & 606723 & 15144247 & 401125 & 13337207 & 14218690 & 50.05 \\
\hline
\end{tabular}

\section{4. 资源型城市转型效率分析}

运用dea-solver pro5.0对山西省10个资源型城市的转型效果进行测评, 从测算结果来看 (见 表2），转型效果在 1 以上的约占 $2 / 5$, 转型效果在 1 以下的约占 $3 / 5$, 山西省资源城市转型初见 成效。其中, 大同、长治、晋城、晋中、运城、临汾 6 个城市的平均转型效率值均小于 1 ; 转 型效果最弱的是晋中，转型压力较大，转型效果最强的是吕梁，转型效果显著。

表2：山西省各个资源型城市的转型效率值

\begin{tabular}{|c|c|c|c|c|c|c|}
\hline DMU & Score(2012) & Score(2013) & Score(2014) & Score(2015) & Score(2016) & $\begin{array}{c}\text { 每年平均 } \\
\text { 效率 }\end{array}$ \\
\hline 大同市 & 0.6086145 & 0.6351033 & 0.6900542 & 0.8755346 & 0.7345375 & 0.708769 \\
\hline 阳泉市 & 1.1736134 & 1.1025604 & 1.091093 & 1.2275409 & 1.1557807 & 1.150118 \\
\hline 长治市 & 0.8481866 & 0.7274935 & 0.9300701 & 0.9071934 & 0.8781386 & 0.858216 \\
\hline 晋城市 & 0.8740959 & 0.8473007 & 1.0000959 & 1.0269662 & 0.9315404 & 0.936 \\
\hline 朔州市 & 1.6897262 & 1.5151594 & 1.4779394 & 1.3300706 & 1.5351356 & 1.509606 \\
\hline 晋中市 & 0.6479753 & 0.6379967 & 0.7546742 & 0.6994528 & 0.6783604 & 0.683692 \\
\hline 运城市 & 0.6930362 & 1.2420386 & 1.0357952 & 1.0139932 & 0.8056555 & 0.958104 \\
\hline 忻州市 & 1.5081394 & 1.2514006 & 1.4048242 & 1.5150868 & 1.4494473 & 1.42578 \\
\hline 临汾市 & 0.9017824 & 0.9053537 & 1.0313679 & 1.0466567 & 1.0530505 & 0.987642 \\
\hline 吕梁市 & 2.2372608 & 1.3782462 & 1.181034 & 2.0805565 & 1.7526508 & 1.72595 \\
\hline 平均值 & 1.118243 & 1.024265 & 1.059695 & 1.172305 & 1.09743 & 1.094388 \\
\hline
\end{tabular}

10个资源型城市 2012-2016年平均效率值为1.094388, 表明山西省各个市的转型效果总 体较好; 从时间变化角度看, 山西各个城市每年转型效果平均值介于 1.0 到 1.2 之间, 上升 趋势并不明显, 山西省资源型城市的转型尚未取得突破性进展。从各个城市5年的平均效率值 来看, 吕梁市、朔州市和忻州市的转型效果最好, 其效率值分别为1.72595、1.509606和1.42578。

\section{DMU生产前沿面优化分析}

为了更加详细地分析山西省各个资源型城市转型效果，本文对山西省 10 个资源型城市 2014年的投入指标（工业用电量、固定资产投入）进行优化分析（见表3），比较投入指标的 原始值和生产前沿面的投影值。 
表3:2014年山西省各个资源型城市投入要素优化分析

\begin{tabular}{|c|c|c|c|c|c|c|}
\hline \multirow{2}{*}{ 城市 } & \multicolumn{3}{|c|}{ 工业用电量 (万千瓦时) } & \multicolumn{3}{c|}{ 固定资产投入 (万元) } \\
\cline { 2 - 7 } & 原始值 & 投影值 & 优化潜力 & 原始值 & 投影值 & 优化潜力 \\
\hline 大同市 & 569453 & 403420.8 & $29.16 \%$ & 10724080 & 8330101.9 & $22.32 \%$ \\
\hline 阳泉市 & 460419 & 460419 & $0.00 \%$ & 5173685 & 6587545.1 & $-27.33 \%$ \\
\hline 长治市 & 273251 & 215925.77 & $20.98 \%$ & 12456466 & 12456466 & $0.00 \%$ \\
\hline 晋城市 & 115152 & 115152 & $0.00 \%$ & 9747818 & 9750622.8 & $-0.03 \%$ \\
\hline 朔州市 & 473097 & 473097 & $0.00 \%$ & 8152983 & 13181131 & $-61.67 \%$ \\
\hline 晋中市 & 143200 & 76581.762 & $46.52 \%$ & 11060072 & 9993844 & $9.64 \%$ \\
\hline 运城市 & 103280 & 103280 & $0.00 \%$ & 12027349 & 13318914 & $-10.74 \%$ \\
\hline 忻州市 & 69400 & 89067.039 & $-28.34 \%$ & 9654225 & 10566447 & $-9.45 \%$ \\
\hline 临汾市 & 171450 & 171450 & $0.00 \%$ & 12294284 & 12294284 & $0.00 \%$ \\
\hline 吕梁市 & 78500 & 115640.15 & $-47.31 \%$ & 10169695 & 10525346 & $-3.50 \%$ \\
\hline
\end{tabular}

从表 3 可以看出, 大同、长治、晋中需要对工业用电量进行优化, 优化潜力分别为 $29.16 \%$, $20.98 \%$, 46.52\% ; 大同、晋中需要对固定资产投入进行优化，优化潜力分别为 $22.32 \%, 9.64 \%$ 。 其余城市指标优化潜力为 0 , 投入指标的原始值与投影值相同, 表明该指标投入合理, 无需进 行优化。

\section{6. 结论与建议}

山西省2014年达到最优生产前沿面的城市数量较多, 城市转型取得初步效果。具体而言, 晋中、大同的转型效率最不理想, 吕梁、朔州、忻州的转型效果最好。晋中的优化潜力较高, 说明对资源依赖程度高, 产业转型难度较大。

1) 各级政府加强对产业结构的优化调整，扶持第三产业和战略新兴产业，加快产业结构 的优化升级。2）针对各个城市的具体情况具体分析, 打破资源诅咒, 选择适宜的发展方式。 3 ) 采取科学的措施, 加强对科教的投入, 改善城市人文、生态环境, 为资源型城市转型探索 出一条高效合理的路径。

\section{References}

[1]Zeng Xian-gang and Duan Cun-ru, Performance evaluation and differential analysis on green transformation of coal resource-exhausted cities in China,int J. China Population,Resources and Environment,vol.28,pp.127-135,2018.

[2]SUN Qinglin,HU Xiaoming and WANG Siyuan, Planned Response to the Transformation and Development of Coal Resource-based Cities in the New Era: Taking the "Urban Master Plan of Huainan City (2016-2035) " as an Example, int.J. Urban Development Studies,vol.25,pp.5-9,2018.

[3]HAO Zu-tao,FENG Bing,XIE Xiong-biao,FENG Zhong-lei and WANG Ying, Research on Performance Measure and Group Difference during Transformation of Resource-based Cities Based on Livelihood Satisfaction_-A Case Study of Huangshi City in Hubei Province, int.J.Journal of Natural Resources,vol.32,pp.1298-1310,2017.

[4]XU Jun,LI Qiao-hui and WANG Yu-hong, Integrated mechanism of resource-based cities transformation driven by the supply reform, int.J. China Population,Resources and Environment,vol.26,pp.53-60,2016.

[5] CAO Jian-zhong and WANG Hai-feng, Research on Transformation Efficiency of Resource-based Cities Based on the Dynamic SBM and Meta Frontier Model Covering Bad Output, int.J. Soft Science,vol.30,pp.117-120,2016. 